\title{
World tuberculosis day 2016
}

\section{Editorial}

In 1982, on the one-hundred anniversary of Robert Koch's Tuberculosis presentation to the scientific community that he had discovered the cause of tuberculosis (TB), the TB bacillus, the "International Union against Tuberculosis and Lung Disease (IUATLD)" proposed that $24^{\text {th }}$ of March be proclaimed as an annual official event, the "World Tuberculosis Day". This was established by the effort of both the World Health Organization (WHO) and the IUATLD under the theme "Defeat TB: Now and forever". Nevertheless, it was not announced as an official event to be celebrated annually by the WHO's World Health Assembly and the United Nation. At the time of Koch's announcement in Berlin, TB was raging through Europe and the Americas, causing the death of one out every seven persons. Koch's discovery opened the way toward diagnosing and curing TB. Today, TB causes the deaths of about 1.7 million people, annually, mostly in the Third World. The first World Tuberculosis Day celebration meeting was held by the WHO and the Royal Netherlands Tuberculosis Foundation (KNCV) in 1995 in Den Haag, Netherlands where it was declared to be celebrated annually. In 1996, the WHO joined with the IUATLD and various concerned organizations to organize variety of activities and events and increase the impact of the World Tuberculosis Day.

In 1997, Directly Observed Treatment, Short Course (DOTS) was declared as a biggest step taken against TB by the WHO in the press conference of Berlin. Due to the global situation of this epidemic disease, almost 200 organizations were joined to perform the awareness activities on the World Tuberculosis Day of 1998 where top 22 most affected countries with TB were announced by the WHO in the press conference in London. A new network "Stop TB Partnership" has been established by the various organizations to fight against TB by highlighting the scope of prevention and cure of the disease to the common public. Currently, the International Committee
Volume 3 Issue 2 - 2016

\author{
Attapon Cheepsattayakorn, ${ }^{1,2,3}$ Ruangrong \\ Cheepsattayakorn ${ }^{4}$ \\ 'Editor-in-Chief, Journal of Lung, Pulmonary and Respiratory \\ Research, USA \\ ${ }^{2}$ Oth Zonal Tuberculosis and Chest Disease Center, Chiang Mai, \\ Thailand \\ 35th Office of Disease Prevention and Control, Ratchaburi, \\ Department of Disease Control, Ministry of Public Health, \\ Thailand \\ ${ }^{4}$ Department of Pathology, Faculty of Medicine, Chiang Mai \\ University, Chiang Mai, Thailand
}

Correspondence: Attapon Cheepsattayakorn, I0th Zonal Tuberculosis and Chest Disease Center, I 43 Sridornchai Road Changklan Muang Chiang Mai 50I00 Thailand, Tel 6653 I40767, 6653 276364, Fax 6653 140773, 665327359

Email Attapon1958@gmail.com, attaponche@yahoo.com

Received: March 18, 2016| Published: March 24, 2016

of the Red Cross (ICRC) is assisting people to fight against TB in prisons due to the poor nutrition and overcrowding. The theme of the World Tuberculosis Day celebration was different year by year, while the theme of the year 2016 would be "Unite to End TB".

\section{Acknowledgements}

None.

\section{Conflict of interest}

The author declares no conflict of interest. 